\title{
EFEKTIFITAS TERAPI AKUPUNKTUR MENGGUNAKAN KOMBINASI TITIK ZUSANLI (ST36), TITIK SANYINJIAO (SP6), TITIK YANGLINGQUAN (GB34) DAN TITIK TAIXI (KI3) UNTUK PENURUNAN NYERI PADA OSTEOARTHRITIS DI GRIYA SEHAT PRIMA HATI SURAKARTA
}

\author{
Maria Dewi Christiyawati \\ Kementerian Kesehatan Politeknik Kesehatan Surakarta Jurusan Akupunktur
}

\begin{abstract}
Osteoarthritis, The Point Of Sanyinjiao (SP6), The Point Of Taixi (KI3), Yanglingquan (GB34), And Point Zusanli (ST36). Osteoarthritis (OA) is a degenerative disorder that is on the mark with loss of cartilage. Based on the preliminary studies have been conducted on the elderly in Griya Sehat Prima Hati Surakarta, 18 elderly pleased given acupuncture therapy. Acupuncture therapy on a case of Osteoarthritis can improve blood circulation, improve the cartilage matrix, reducing the narrowing of joint bones and eliminate pain in knee Osteoarthritis cases. The purpose of this research is to know is there anyThe Influence Of Acupuncture Therapy Using A Combination Of Point Zusanli (ST36), Point Sanyinjiao (SP6), Yanglingquan Point (GB34), And The Point Of Taixi (KI3) to decrese pain in cases of Osteoarthritis elderly in the village of Kiringan and Umbulsari Klaten Polanharjo Ponggok. The research conducted during the month of September 2016 until June 2017 in Griya Sehat Prima Hati Surakarta with make pricking uses a Combination of Point Zusanli (ST36), the point of Sanyinjiao (SP6), Yanglingquan Point (GB34), and the point of Taixi (KI3). The therapy performed during 12 times therapy. This type of research this is a Pretest-Posttest Experimental pre that use design research One Group Pretest - Posttest Design. The data analyzed using paired t-test with significant degrees of 0.05. Measurement of pain sensations using a Numeric Rating Scale (NRS) (patient own set skore pain pain range). Statistical Tests by using the test of Paired $t$ test values available by sifgnifikan $p=0.000$, if $\rho<0.05$ then Ho was rejected and Ha be accepted meaning therapy acupuncture Zusanli (ST36) point, the point of Sanyinjiao (SP6), Yanglingquan point (GB34), and the point of Taixi (KI3) have benefits to reduce pain in cases of Osteoarthritis (OA).
\end{abstract}

Keywords: Osteoarthritis, The Point Of Sanyinjiao (SP6), The Point Of Taixi (KI3), Yanglingquan (GB34), And Point Zusanli (ST36).

Abstrak : Osteoarthritis, Titik Sanyinjiao (SP6), Titik Taixi (KI3), Yanglingquan (GB34), Dan Titik Zusanli (ST36). Osteoarthritis (OA) merupakan gangguan degeneratif yang ditandai dengan hilangnya kartilago. Responden pada penelitian ini 18 lansia diantaranya berkenan diberikan terapi akupunktur. Pemberian terapi akupunktur pada kasus Osteoarthritis dapat memperbaiki sirkulasi darah, memperbaiki matriks tulang rawan, mengurangi penyempitan tulang sendi dan menghilangkan rasa nyeri pada kasus Osteoarthritis lutut. Tujuan Penelitian ini yaitu untuk mengetahui Adakah Pengaruh Terapi Akupunktur Menggunakan Kombinasi Titik Zusanli (ST36), Titik Sanyinjiao (SP6), Titik Yanglingquan (GB34), Dan Titik Taixi (KI3) Terhadap 
Penurnan Nyeri Pada Kasus Osteoarthritis Di Dusun Kiringan dan Umbulsari Desa Ponggok Polanharjo Klaten. Penelitian dilakukan selama bulan Maret 2017 sampai dengan April 2017 di Griya Sehat Prima Hati Surakarta. dengan melakukan penusukan Menggunakan Kombinasi Titik Zusanli (ST36), Titik Sanyinjiao (SP6), Titik Yanglingquan (GB34), Dan Titik Taixi (KI3). Terapi dilakukan selama 12 kali terapi. Jenis penelitian ini adalah pre eksperimentalPretest-Posttest yang menggunakan rancangan penelitian One Group Pretest-Posttest Design. Data dianalisis dengan menggunakan uji paired t-test dengan taraf signifikan 0,05. Pengukuran sensasi nyeri menggunakan Numeric Rating Scale (NRS) (pasien sendiri yang menetapkan skore nyeri pada rentang nyeri). Uji statistika dengan menggunakan uji paired t-test didapatkan nilai sifgnifikan $\mathrm{p}=0,000$, jika $\rho<0,05$ maka Ho ditolak dan Ha diterima artinya terapi akupunktur titik Zusanli (ST36), titik Sanyinjiao (SP6), titik Yanglingquan (GB34), Dan titik Taixi (KI3) memiliki manfaat untuk mengurangi nyeri pada kasus Osteoarthritis (OA).

Kata Kunci : Osteoarthritis, Titik Sanyinjiao (SP6), Titik Taixi (KI3), Yanglingquan (GB34), Dan Titik Zusanli (ST36).

\section{PENDAHULUAN}

Angka kejadian ada tahun 2012 Oasteoarthritismenyerang $15 \%$ populasi di Inggris yang berusia lebih dari 55 tahun (Gray\&Houghton, 2012). Menurut Kneale dan Davis tahun 2011 bahwa $50 \%$ individu yang berusia lebih dari 60 tahun menunjukkan mengalami Osteoarthritis pada satu sendi. Prevalensi di Amerika pada tahun 2005 Osteoarthritis menyerang 40 juta orang sekitar $30 \%$ sampai $60 \%$ yang berusia 65 tahun. Prevalensi Osteoarthritis di Indonesia pada usia kurang dari 20 tahun hanya sekitar $10 \%$ dan meningkat menjadi lebih dari $80 \%$ pada usia diatas 55 tahun. Penderita Osteoarthritis di Indonesia cukup tinggi mencapai $15,5 \%$ pada pria dan 12,7\% pada wanita (Soeroso et al., 2006). Di Jawa Tengah, kejadian penyakit Osteoarhtritis sebesar 5,1\% dari semua penduduk (Kongres Nasional Ikatan Reumatologi Indonesia VI,2004).

Osteoarthritis sendi lutut bertujuan untuk mengurangi nyeri dengan menggunakan obat (farmakologis) dan tanpa obat (non farmakologis). Terapi akupuntur merupakan salah satu terapi non farmakologis yang dapat menurunkan nyeri. Titik akupunktur merupakan jalur saraf yang bertujuan untuk memperbaiki kesehatan. Menurut National Centre for Complementary and Alternative Medicine tahun 2004 bahwa akupunktur berguna sebagai terapi tambahan atau terapi untuk nyeri arthritis. Efek akupunkturpada titik lokal yang dikombinasi dengan titik distal,padakasus Osteoarthritis cukup signifikan.

Menurut Slamet (2012) pemberian terapi akupunktur pada kasus Osteoarthritis dapat memperbaiki sirkulasi darah, memperbaiki matriks tulang rawan, mengurangi penyempitan tulang sendi dan menghilangkan rasa nyeri.

Menurut McAlindron TE et al., tahun 2000 Dalam Paul et al., tahun 2012 bahwa akupunktur dapat berguna dalam penalataksanaan nyeri dan memperbaiki fungsi. Terdapat lebih banyak perbandingan antara akupunktur dan 
pengobatan konvensional untuk Osteoarthritis pada punggung dan lutut dibanding sendi lain. Akupunktur setara dengan pengobatan oral untuk gejala ringan pada Osteoarthritis punggung dan lutut.

Secara umum tujuan penelitian ini adalah untuk mengetahui efektifitas Terapi Akupunktur Menggunakan Kombinasi Titik Zusanli (ST36),Titik Sanyinjiao (SP6), Titik Yanglingquan (GB34), Dan Titik Taixi (KI3) untuk Penurnan Nyeri Pada Kasus Osteoarthritis Di Griya Sehat Prima Hati Surakarta.

Osteoarthritis adalah penyakit yang sering terjadi pada orang lanjut usia dan selama ini orang yang terkena Osteoarthritis hanya melakukan pengobatan dengan cara minum obat. Jarang sekali yang langsung melakukan terapi alternatif dengan menggunakan terapi akupunktur untuk mengobati keluhan tersebut karena sebagian banyak orang tidak mengetahui manfaat dari akupunktur yaitu dapat menurunkan

nyeri terutama nyeri pada kasus Osteoarthritis.

\section{METODE PENELITIAN}

Penelitian dilaksanakan di Griya Sehat Prima Hati Surakarta. Dilkukan pada bulan September 2016 sampai dengan bulan Juni 2017. Penelitian ini menggunakan desain penelitian pre eksperimental Pretest-Post test One Group Design. Pretest-Postest One Group Design adalah membandingkan sebelum dilakukan (pretest) dengan sesudah dilakukan perlakuan terapi Akupunktur (postest) (Sugiono, 2008).

Responden dalam penelitian ini sejumlah 18 orang. Variabel bebas pada penelitian ini adalah Akupunktur Kombinasi Titik Zusanli (ST36), Titik
Sanyinjiao (SP6), Titik Yanglingquan (GB34), dan Titik Taixi (KI3).

Alat ukur yang digunakan dalam penelitian ini adalah Numeric Rating Scale (NRS).

\section{HASIL PENELITIAN}

Tabel 1

Distribusi Frekuensi Responden

Berdasarkan Pekerjaan di Griya Sehat Prima Hati Surakarta tahun 2017.

\begin{tabular}{lcc}
\hline Pekerjaan & Frekuensi & Persentase (\%) \\
\hline Buruh & 3 & 17 \\
Perangkat & 2 & 11 \\
IRT & 6 & 33 \\
Swasta & 6 & 33 \\
PNS & 1 & 6 \\
\hline \multicolumn{1}{c}{ Jumlah } & 18 & 100 \\
\hline
\end{tabular}

Dari data tabel 1 tersebut dapat disimpulkan bahwa frekuensi terbanyak adalah responden dengan sebagai IRT atau Ibu Rumah Tangga. Jenis pekerjaan terbanyak adalah Swasta sebesar $33 \%$ dan yang paling

Tabel 2

Distribusi Skala Nyeri Responden Sebelum Terapi di Griya Sehat Prima Hati Surakarta tahun 2017.

Nyeri sebelum terapi $\quad$ Frekuensi $\quad$ Persentase

\begin{tabular}{ccc}
\hline 3 & 3 & 16.7 \\
4 & 3 & 16.7 \\
5 & 5 & 27.8 \\
6 & 4 & 22.2 \\
7 & 3 & 16.7 \\
\hline Jumlah & 18 & 100.0 \\
\hline
\end{tabular}

Berdasarkan data tabel 2. sebelum terapi skala nyeri maksimum ada pada skala 7 dan minimum pada skala 3, dengan rata-rata skala nyeri adalah 5.06. Responden dengan skala nyeri 5 paling banyak yaitu 5 orang $(27,8 \%)$, sedangkan skala nyeri $3,4,7$. sedikit 3 orang $(16,7 \%)$ 
Tabel 3

Distribusi Frekwensi Skala Nyeri Responden Sesudah Terapi di Griya Sehat Prima Hati Surakarta Tahun 2017

\begin{tabular}{ccc}
\hline Nyeri sesudah terapi & Frekuensi & Persentase \\
\hline 2 & 3 & 16.7 \\
3 & 5 & 27.8 \\
4 & 5 & 27.8 \\
5 & 3 & 16.7 \\
6 & 2 & 11.1 \\
\hline Jumlah & 18 & 100.0 \\
\hline
\end{tabular}

Dari tabel 3 didapatkan data sesudah terapi nilai maksimum adalah skala nyeri pada skala 6 dan minimum pada skala 2 , dengan rata-rata skala nyeri adalah 3.78. Responden dengan skala nyeri 3 dan 4 paling sebanyak 5 orang (27.8\%), sedangkan paling sedikit 2 orang (16.7\%) dengan skala nyeri yaitu 6.

\section{Hasil Uji Statistik}

Hasil Uji Normalitas data menggunakan uji statistik Saphiro-wilk karena data yang didapatkan berskala nominal dan berdistribusi normal.

\section{Tabel 4}

Hasil Uji Normalitas Data Menggunakan Saphiro-Wilk

\begin{tabular}{cccc}
\hline Karakteristik & N & Saphiro-wilk \\
\hline Sebelum Terapi & 18 & 0,107 & \\
Sesudah Terapi & 18 & 0,135 & \\
\hline Hasil & uji & \multicolumn{3}{c}{ Saphiro } & Wilk
\end{tabular}
menunjukkan bahwa nilai Sig (signifikan) skala nyeri responden sebelum diterapi adalah 0,107 dan signifikasi penurunan skala nyeri setelah terapi adalah 0,135 . Hal ini dapat disimpulkan bahwa data berdistribusi normal karena nilai signifikan lebih dari 0,05 (Duwi, 2010). Karena data berdistribusi normal maka pengujian hipotesis dengan menggunakan uji paired t-test untuk mengetahui perbedaan skala nyeri sebelum dan sesudah dilakukan terapi akupunktur.

Pada uji paired t-test didapatkan nilai signifikan $\rho=0,000$, jika $\rho<0,05$ maka Ho ditolak dan Ha diterima artinya terapi akupunktur menggunakan kombinasi titik Zusanli (ST36), titik Sanyinjiao (SP6), titik Yanglingquan (GB34), Dan titik Taixi (KI3) efektif untuk mengurangi nyeri pada kasus Osteoarthritis (OA).

\section{PEMBAHASAN}

Dalam TCM pada orang tua biasanya terjadi barbagai macam keluhan nyeri dipicu dari kondisi tubuhnya yang mulai defisien. Usia tua akan menyebabkan terjadinya penurunan fungsi pada organ hati dan ginjal serta disertai adanya kondisi defisien Qi dan darah. Hal tersebut menyebabkan sendi, otot, tendon, tulang dan pembuluh darah kurang ternutrisi dengn baik sehingga muncul gejala nyeri pada sendi (Wang, 2007).

Hal ini sesuai dengan tinjauan teori menurut Partojo (2000) dimana pekerjaan aktivitas fisik yang banyak membebani sendi lutut akan mempunyai resiko teserang osteoarthritis (OA) lebih besar. Selain itu diperkuat pada penelitian Setiyohadi pada tahun 2003 mengenai osteoarthritis (OA) banyak ditemukan pada pekerja fisik berat terutama yang banyak menggunakan kekuatan yang bertumpu pada lutut.

Dalam TCM Overwork dapat menyebabkan berkurangnya essens ginjal yang menyebabkan tubuh menjadi lemah dan nyeri pada sendi (Sim, 2012). Faktor trauma yang terjadi pada sendi akan merusak tendon dan pembuluh darah. Mikro maupun makro trauma dapat mengakibatkan tidak lancarnya aliran Qi dan darah pada anggota tubuh. Sehingga 
terjadi obstruksi yang menggangu Qi dan darah pada meridian tubuh. Sehingga terjadi obstruksi yang menggangu Qi dan darah pada meridian oleh karena itu muncul gejala nyeri pada sendi (Wang, 2007).

hasil $\begin{gathered}\text { Dari hasil uji hipotesa di dapatkan } \\ \text { bahwa terapi dengan }\end{gathered}$ elektroakupunktur sangat efektif terhadap penurunan skala nyeri pada kasus osteoarthritis (OA)di Griya Sehat Prima Hatis Surakarta. seperti yang dipaparkan sebelumnya di ketahui bahwa rata-rata penurunan skala nyeri responden sebelum diterapi adalah sebesar 5,06. Dan didapatkan data bahwa rata-rata penurunan skala nyeri responden sesudah dilakukan terapi adalah sebesar 3,78. Sehingga didapatkan rata-rata dari hasil pengurangan mean skala nyeri sebelum perlakuan terapi akupunktur dan sesudah perlakuan terapi akupunktur sebesar 1,28. Pada Uji Hipotesa juga di dapatkan data yang menunjukkan hasil uji sampel yaitu $\rho$ value $0,000<0,05$, dengan demikian maka dapat disimpulkan bahwa terapi elektroakupunktur efektif terhadap penurunan skala nyeri pada kasus osteoarthritis(OA).

Selain melalui jalur saraf, tindakan akupunktur dalam menghilangkan nyeri diketahui juga melalui jalur biokimia atau mekanisme humoral. Dalam perjalanannya menyeberangi sinaps atau hambatan antar saraf, impuls saraf harus dijembatani oleh substansi kimiawi yang disebut neurotransmitter. Dengan demikian dapat disimpulkan bahwa akupunktur mempunyai manfaat merangsang jalur modulasi melalui pelepasan neurotransmiter inhibitor terutama endorfin, dinorfin, serotonin, dan noradrenalin, enkefalin (Sudirman , 2008).
Pada uji paired t-test didapatkan nilai signifikan $\rho=0,000$, jika $\rho<0,05$ maka Ho ditolak dan Ha diterima artinya Terapi Akupunktur Menggunakan Kombinasi Titik Zusanli (ST36), Titik Sanyinjiao (SP6), Titik Yanglingquan (GB34), Dan titik Taixi (KI3) efektif dan bermanfaat untuk mengurangi nyeri pada kasus Osteoarthritis (OA).

Berdasarkan hasil uji hipotesa stastika Terapi Akupunktur Menggunakan Kombinasi Titik Zusanli (ST36), Titik Sanyinjiao (SP6), Titik Yanglingquan (GB34), Dan titik Taixi (KI3) efektif dan bermanfaat dapat menurunkan atau mengurangi nyeri Osteoarthritis (OA). Responden yang mengeluhkan Osteoarthritis (OA) setelah terapi akupunktur mengalami berubahan skala nyeri sebanyak $1-2$, penurunan skala nyeri. Penurunan skala nyeri tidak didapatkan hasil menurun banyak dan signifikan dikarenakan responden masih tetap melakukan aktivitas rutin yang menjadi penyebab nyeri yang dialami. Responden juga tidak tidak dapat mengurangi aktivitas yang dapat memperparah terjadinya Osteoarthritis $(O A)$.

\section{KESIMPULAN DAN SARAN}

Dari hasil penelitian dapat disimpulkan bahwa pada penelitian ini terdiri dari 18 responden dengan hasil sebagai berikut sebelum terapi skala nyeri maksimum ada pada skala 7 dan minimum pada skala 3, dengan rata-rata skala nyeri adalah 5.06. Responden dengan skala nyeri 5 paling banyak yaitu 5 orang $(27,8 \%)$, sedangkan skala nyeri $3,4,7$. sedikit 3 orang $(16,7 \%)$. sesudah terapi nilai maksimum adalah skala nyeri pada skala 6 dan minimum pada skala 2 , dengan rata-rata skala nyeri adalah 3.78 . 
Responden dengan skala nyeri 3 dan 4 paling sebanyak 5 orang $(27.8 \%)$, sedangkan paling sedikit 2 orang $(16.7 \%)$ dengan skala nyeri yaitu 6 . Berdasarkan hasil uji hipotesa stastika Terapi Akupunktur Menggunakan Kombinasi Titik Zusanli (ST36), Titik Sanyinjiao (SP6), Titik Yanglingquan (GB34), Dan titik Taixi (KI3) efektif dan bermanfaat dapat menurunkan atau mengurangi nyeri Osteoarthritis (OA). Pada uji paired t-test didapatkan nilai signifikan $\rho=0,000$, jika $\rho<0,05$ maka Ho ditolak dan Ha diterima artinya terapi akupunktur menggunakan kombinasi titik Zusanli (ST36), titik Sanyinjiao (SP6), titik Yanglingquan (GB34), Dan titik Taixi (KI3) efektif untuk mengurangi nyeri pada kasus Osteoarthritis (OA).Saran yang dapat disampaikan dari hasil penelitian ini adalah pada penelitian selanjutnya diharapkan menggnakan kelompok komtrol dan jumlah responden lebih banyak. Diperlukan kriteria inklusi penelitian yang lebih spesifik.

\section{DAFTAR RUJUKAN}

Dodik, Gede, Dodik, Keristianto., Ns. I Wayan, Suardana, S.Kep, M.Kep., Ns. Made, Sumarni, S.Kep. 2013. Pengaruh Terapi Akupunktur Terhadap Penurunan Nyeri Lutut Pada Pasien Dengan Osteoarthritis Di Praktik Perawat Mandiri Latu Usadha Abiansemal. Denpasar: Jurnal Ilmu Keperawatan Fakultas Kedokteran Universitas Udayana.

Hargiyanto. (2008). Perbedaan Efek Analgesia Tindakan Elektroakupunktur Dengan Frekuensi Rendah, Kombinasi, dan Tinggi, Pada Nyeri Punggung Bawah. Tesis. Jawa Tengah,
Surakarta: Universitas Sebelas Maret.

Ikatan Reumatologi Indonesia (IRA). 2004. Panduan Diagnosis dan Pengelolahan Osteoarthritis. Jakarta. Hal 39-45.

International Association for The Study Of Pain (IASP). 2003. Older People's Pain. Juli 09, 2012.

Mahajan, A., Tandon, V., Verma, S,. Sharma, S. 2005. Osteoarthtritis and Menopause. J Indian Rheumatol Assoc 2005; 13:21-25.

Muchid, A., Umar, F., Chusun., Purnama, N.R., Masrul., Lestari, S.B., et al. 2006. Pharmaceutical Care Untuk Pasien Penyakit Arthritis Rematik. Jakarta: Direktorat Bina Farmasi Komunitas dan Klinik Ditjen Bina Kefarmasian dan Alat Kesehatan Departemen Kesehatan.

National Centre for Complementary and Alternative Medicine. 2004. Acupuncture. Available at: http//nccam.nih.gov.html

Prasetyo, Sigit, Nian. 2010. Konsep dan Proses Keperawatan Nyeri. Edisi I. Yogyakarta: Graha Ilmu.

Price, S. A., Wilson, L. M. 2013. Patofisiologi Konsep Klinis Proses-Proses Penyakit, Ed 6. Jakarta : EGC.

Sim, K.J. 2012. Dasar Teori Ilmu Herbal dan AkupunkturIndikasi dan Klasifikasi Penyakit. Singapore: TCM Publication.

Sudirman S. 2008. Akupunktur untuk nyeri pasca bedah. Annual Meeting of Indonesia Pain Society. Jakarta : Indonesia Pain Society.

Suhariningsih. 2004. Pedoman Penggunaan Elektrostimulator dan Laser pada Terapi akupunktur. Surabaya: Airlangga Press 
Wang, Y. 2007. Internal Medicine of Traditional Chinese Medicine. Chinese : Higher Education Press.

Wolf, C.J., 2004. Pain: Moving from Symptom Control to ward Mechanism-Specific harmacologic Management, Ann Intern Med.

Xinghua, B. 1996. Accupuncture in Clinical Practice. Melbourne: The Bath Press. 